



\section{Role of Water in}

\section{Urban Planning and}

\section{Management}

By William J. Schneider, David A. Rickert,

and Andrew M. Spieker

WATER IN THE URBAN ENVIRONMENT

GEOLOGICAL SURVEY CIRCULAR 601-H 


\section{United States Department of the Interior}

ROGERS C. B. MORTON, Secrefary

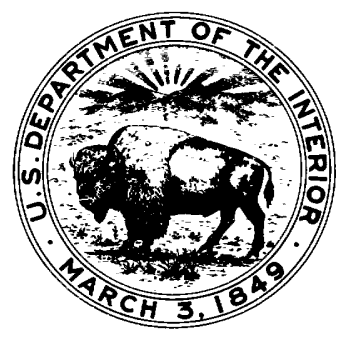

Geological Survey

V. E. McKelvey, Director

First printing 1973

Second printing 1973

Free on application to the U.S. Geological Survey, Washington, D.C. 20242 


\section{FOREWORD}

Urbanization - the concentration of people in urban areas and the consequent expansion of these areas - is a characteristic of our time. It has brought with it a host of new or aggravated problems that often make new demands on our natural resources and our physical environment. Problems involving water as a vital resource and a powerful environmental agent are among the most critical. These problems include the maintenance of both the quantity and quality of our water supply for consumption, for recreation, and general welfare and the alleviation of hazards caused by floods, drainage, erosion, and sedimentation.

A prerequisite to anticipating, recognizing, and coping intelligently with these problems is an adequate base of information. This series of reports is intended to show the relevance of water facts to water problems of urban areas and to examine the adequacy of the existing base of water information.

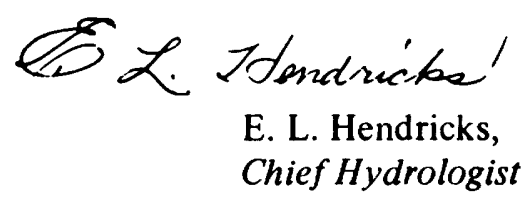





\section{CONTENTS}

Page

Abstract ---

Introduction -

Urban impact on water resources

Purpose of circular

Water in urban planning and management

Relationship to overall natural resources

Regional approach 3

Integration into urban planning and management

Types of information - 4

Relation to planning

Hydrologic elements of urban water appraisals

Relationship of hydrologic data to urban problems

An evaluation matrix . 6

Washington-Baltimore case study

Summary and discussion

\section{ILLUSTRATIONS}

Plate 1. Washington-Baltimore water-resources evaluation matrix In pocket

Figure 1. Simplified flow diagram of the urban planning process showing interrelation of water-resources investigations and planning programs

2. Map showing the Washington-Baltimore urban area

\section{TABLE}

TABLE 1. Sequence of hydrologic analysis applied to land use and planning functions 



\title{
Role of Water in Urban Planning and Management
}

\author{
By William J. Schneider, David A. Rickert, and Andrew M. Spieker
}

\begin{abstract}
Concentrations of people in urban areas intensify water problems such as flooding and pollution, but these deleterious effects on water resources can be minimized or corrected by comprehensive planning and management. Such planning of the water resources of an urban area must be based on adequate hydrologic data.

Through the use of a matrix, urban water problems can be evaluated and availability of data assessed. The Washington-Baltimore metropolitan area is used as a case study. The completed matrix provides both a means for developing a meaningful dialogue between the hydrologist and the urban planner and a method for developing a work plan to insure consideration of water-resources data in urban planning.
\end{abstract}

\section{INTRODUCTION}

Water is a vital resource for human activities. Its natural distribution is governed by climate and the physical character of the land surface. Urbanization, however, has altered this natural distribution as water has been utilized to supply man's needs and to carry away his wastes. Water is, in a sense, both artery and vein to urban life.

\section{URBAN IMPACT ON WATER RESOURCES}

Urbanization has significantly altered both the quantity and quality of our water resources. The concentration of people in urban areas has modified the natural landscape, bringing about water problems that strongly affect their daily lives.

Large cities require huge amounts of water to satisfy both domestic and industrial needs. To meet these needs, cities commonly have to divert water long distances at consideral le cost. New York City, for example, diverts water from more than 100 miles away to meet its demands.

Water is used in urban areas to dispose of man's wastes. He disposes of sewage and industrial wastes by discharging them into streams and other water bodies. The severity of the resulting pollution depends upon the derree of waste treatment and on the amount of waste effluent in relation to the amount of water available for dilution. Storm runoff also contributes heavy pollution loads as rainfall flushes contaminants from urban streets. The disposal of solid wastes in dumps and sanitary landfills poses a pollution threat to groundwater resources as water, leaching through the wastes, carries with it both biological and chemical contamination.

Construction of housing and highwiys exposes bare soil to accelerated erosion. In Fairfax County, Virginia, highway construction involving 197 acres contributed 37,000 tons of sediment to the local stream over a 3-year period. This sediment chokes streams 8 .nd fills reservoirs, severely limiting their uses for recreation and esthetic enjoyment and their capacity to accommodate floods.

F'looding is increased by urban development. The roofing and paving of land surfaces and installation of storm sewers concentrate storm runoff and increases the flooding hazard. For example, in a 1-square-mile area, complete storm sewering and paving of 60 persent of the surface-comparable to dense residential 
housing - can increase the average annual flood by a factor of more than four. Such increases in flooding have serious implications when one considers that much of the urban growth in the United States is by encroachment upon flood plains.

In addition to these physical effects on the water resources, urbanization also alters recreational and esthetic values of water bodies. Indiscriminate development of waterfront property has reduced or even destroyed the esthetic appeal and decreased the recreational potential of many areas. Litter and other wastes, as well as general degradation of the local environment, have further depleted the value of the water resource.

Although water resources in urban areas are altered by the urbanization process, the deleterious effects can be minimized or corrected by comprehensive planning and management. But such planning of the water resources of urban areas must be based on adequate hydrologic data.

\section{PURPOSE OF GIRCULAR}

Today a wealth of hydrologic data is available to planners and managers. Much of it, however, is basic data that in its raw form has little, if any, direct application to most urban water problems. These data have been collected either as part of general monitoring networks or as specialized data from specific projects. The principal agency in the collection of these data is the U.S. Geological Survey.

The basic data consists of observations of both surface water and ground water. Surfacewater data are mainly observations of stage and flow; ground-water data are observations of depth to the water table or the pressure head in confined aquifers and of the permeability of aquifer materials. Data on the quality of these waters, mostly on inorganic constituents, are also available. Many other types of special hydrologic data are available. These data are essential to the understanding of our water resources, which is needed for intelligent planning and managing of urban areas.

Although the available hydrologic data represent a significant contribution to management of urban water resources, emerging new approaches to urban planning will require even more data and new ways of prasenting and interpreting these data. During recent years, public awareness of water problems has come about as part of the growing corcern for our deteriorating urban environment. The concern for and the awareness of the environment aspects of urban living have resulted in a changing attitude toward urban planning. In some urban areas the traditional functic nal-economic approaches to planning are being broadened in scope by including consideration of the natural resources of the area.

Furthermore, our present urbar water problems have created a need for new types of data and new techniques of analysis as well as for increased demand for the mor? traditional types of hydrologic data for both planning and management.

In response to these needs, tr? Geological Survey established an Urban Water Program to develop as one of its objectives the capabilities of supplying hydrologic information in a form readily usable by urban cfficials. This circular deals with one major aspect of the program - the adaptation of water-resources information to urban planning and management. It represents the efforts of the $\varepsilon$ uthors, both singly and jointly over a 3-year rariod, in developing a rationale and technique for relating hydrologic information to urban planning and management. Others, of course, have contributed significantly to this development, especially William W. Barnwell, Anchorage, Alaska, and Kenneth E. Vanlier, University, Alabama. Although still preliminary and subject to further revision, the approach has l sen used as the basis for preparing programs for several major urban areas. The rationale and techniques presented herein are intended to stimulate dialogue between hydrologists and planners and to provide a framework for full consideration of water resources in urban $r^{l}$ anning.

\section{WATER IN URBAN PLANNING AND MANAGEMENT}

\section{RELATION TO OVERALL NATURAL RESOURGES}

Public concern over environmental quality has focused sharp attention upon our national resources. The peaceful revolution from exploitation of land, water, and mineral to the conservation and wise use of our natural resources 
has brought with it both concern and understanding of the interrelation of all natural resources. Indeed, it is more than an interrelation; it is an interdependence.

Many examples of interdependence can be cited. Flood magnitudes are related to land characteristics: steep slopes and tight soils accelerate flooding; permeable soils, marshes, swamps, and flood plains attenuate flooding by retarding runoff. Recharge of ground-water reservoirs is dependent upon infiltration characteristics of soils; the degree of siltation of rivers and lakes is determined by erodibility characteristics of these same soils. Minerals leached from the soils by infiltrating rainfall add chemical constituents to the water resource, and its organic composition is altered by decaying vegetation. Water, on the other hand, also influences other natural resources. Landslides and mudslides often result when unstable soils become saturated. Runoff helps shape the topography of the land surface, and streamflow carves valleys and creates flood plains. Water concentrates minerals in usable deposits.

Man's activities have intensified the interrelationship between water and the other natural resources. Water has been generally available to meet the demands of urban areas. Much of the development, however, has been both unilateral and unifunctional in approach: engineering works were designed to supply water to the cities and to carry away the wastes. The result of this approach are apparent. Polluted rivers, rapid eutrophication of lakes, and degraded recreational and esthetic benefits of water resources attest strongly to the need for consideration of all natural resources, including water, in urban planning and management.

\section{REGIONAL APPROACH}

It is becoming increasingly apparent that many, if not most, of the problems facing the Nation's urban areas are regional in nature. The most highly publicized problems are in the areas of crime, drugs, poverty, schools, and transportation, but the problems of the natural environment are rapidly assuming equal importance. Problems of water and air pollution are extremely serious in many areas. Managing the ever-increasing mountain of solid wastes taxes our ingenuity. Maintaining an adequate supply of good-quality water is a problem that has reached near-crisis proportions in some urban areas. All these problems are rerional in scope and transcend local community boundaries. The solutions to these problems must likewise be undertaken on a regional scal..

The regionalization of problems can $\ln$ expected to intensify as urban areas continue to expand and coalesce. In virtually all urban regions, the fragmented governmental iretitutions are ill equipped to deal with rerional problems. As a start towards attacking these regional problems, Councils of Governments have been organized in most metropolitan areas. Some of these councils are assuming operational responsibility for certain functions such as transportation and waste disposel. Regional planning, however, is usually the central unifying activity of a typical Council of Government.

Water management provides an excellent example of the regional scope of urban problems. Typically, water flows in and out of urban areas with no regard for jurisdictional boundaries. The principal source of surface-water supply may be located far upstream from the area itself. Urban areas commonly are served by ground water withdrawn from aquifers whose boundaries do not coincide witl city boundaries. Sewage effluents from sewage treatment plants of cities are discharged to streams, creating problems for urban areas downstream. These water problems require regional solutions.

\section{INTEGRATION INTO URBAN PLANNING AND MANAGEMENT}

Water-resources investigations have not been traditionally considered as components of the urban planning process. This fact is due in large part to the divergent backgrounds of water-resources scientists and urban planners. The water-resources scientist, or hydrologist, is usually trained in the physical sciences (geology, chemistry, geophysics) or engineering, whereas his counterpart, the urban planner, most likely had his training in the social sciences or landscape architecture. The divergent training of physical scientists and social scientists has complicated the communication process necessary for incorporating water-resource 
information into the planning process.

With the increasing emphasis being placed on quality of environment, the urban planner is finding it increasingly necessary to understand the physical system of the region for which he is developing a plan. On the other hand, the same awareness is forcing the hydrologist to consider the context in which he studies the physical system. Water, of course, is an important element of this physical system. Thus, the need for a close working relation between the urban planner and the hydrologist is being recognized, and both are becoming increasingly concerned with environmental factors such as air and water pollution, flood plains, groundwater resources, sand and gravel resources, and unstable soils and slopes. Land-use planning is becoming more environmentally and resource oriented.

Today urban planners are also using increasingly rigorous analytical methods. Theoretical research in regional analyses has evolved a system of modeling of various combinations of regional development, assigning a range of different policies and constraints, and then evaluating the resultant economic and functional consequences. In the evaluation of viable development alternatives, the planner must be aware of the physical system. This awareness includes at least rudimentary understanding of hydrology and other physical sciences. Just as the planner must be aware of the relation of hydrologic factors to his planning, so must the hydrologist be knowledgeable in the processes of urban planning. Together they must develop the development-alternative/resource-impact relationships necessary for sound decision making. Close teamwork is necessary and requires joint understanding of both the resource system and the planning process. In a sense, both the planner and the hydrologist must extend their competences beyond traditional boundaries. This, in turn, will likely lead to development of new disciplines within both professions.

\section{TYPES OF INFORMATION}

Hydrologic information has traditionally consisted of various types of water measurements including river stage, streamflow, depth to ground water, artesian pressure head, and water quality. Records that date back more than 60 years are available. Most of these data are observations and measurements made over a continuing period. In addition to these basic measurements, many types of specialized data and studies are available. In meny cases, the collection of the specialized data was spurred by special need and made possib'o by development of specialized instrumentat: on and measuring techniques. Examples are data on flood profiles, aquifer yields, stream time-of-travel, and salt-water intrusion. More re?ently, waterresources investigations projects have been supplying data on regional bases. Although generally collected for a specific objective, they nevertheless contribute to the overall bank of data vital to the appraisal of we.ter resources of urban areas.

Also needed-and available-are hydrologically related data. For example, data on watersupply systems and wastewater disposal facilities are important as a set of Tydrologically related data, as are data on many other cultural developments such as locations of areas served by septic tanks and sewer systems and locations of sites and types of solid-waste disposal.

Some hydrologic information can be directly integrated into the urban planring process; other information, to be useful tc the planner, must be analyzed, interpreted, and sometimes combined with other kinds of data.

\section{RELATION TO PLANNIN'G}

The goal of the urban planner is to guide the future development and growth of cities and regions to minimize problems and optimize the quality of living. Thus, the many and diverse forces that create pressures for growth and renewal of the urban environment are the principal concern of the urban planner. Guidelines for future development are usually expressed in a comprehensive plan that proposes the future arrangement of uses of land, such as residential, commercial, industrial, transportation facilities, schools, hospitals, parks, and open space. The comprehensive r'an is based on studies of current conditions $\varepsilon$.nd forecasts of population growth, anticipated future land uses, social changes, transportation, prospects for future commercial and industrial development, governmental policies, and other factors which may influence urban development. 
Thus, planning is a complex and multifaceted process that attempts to integrate all the physical, economic, social, and political implications of urban development into an orderly plan. Land-use planning is the part of this larger process that is concerned with the location and density of development of the various space-demanding functions of urban activity.

The water-resources system is in reality a subsystem of the physical urban system. Therefore the planner must consider the waterresources subsystem in the broader context of all the other subsystems. In order for him to consider this water-resources subsystem, however, he must have information available to him in formats that he can understand and use. However, the traditional products of the hydrologist are not always easily understood by those involved in urban planning.
The development of useful products involves a partnership between the hydrologist and the urban planner and an evolution of products from basic data through stages of compilation and interpretation to user-oriented products. Figure 1 is a simplified flow diagram which illustrates the evolution of such an interdisciplinary effort. The effort begins with the identification of problems and definition of objectives. The ultimate goal is improve development. This goal can be approached, as shown in the diagram, by following two parallel paths. The upper path represents the activities of the urban planner, and the lower path represents the inputs of the water-resources scientist. Inherent in the activities of the urban planner are all planning considerations, including technical, institutional, legal, and political items.

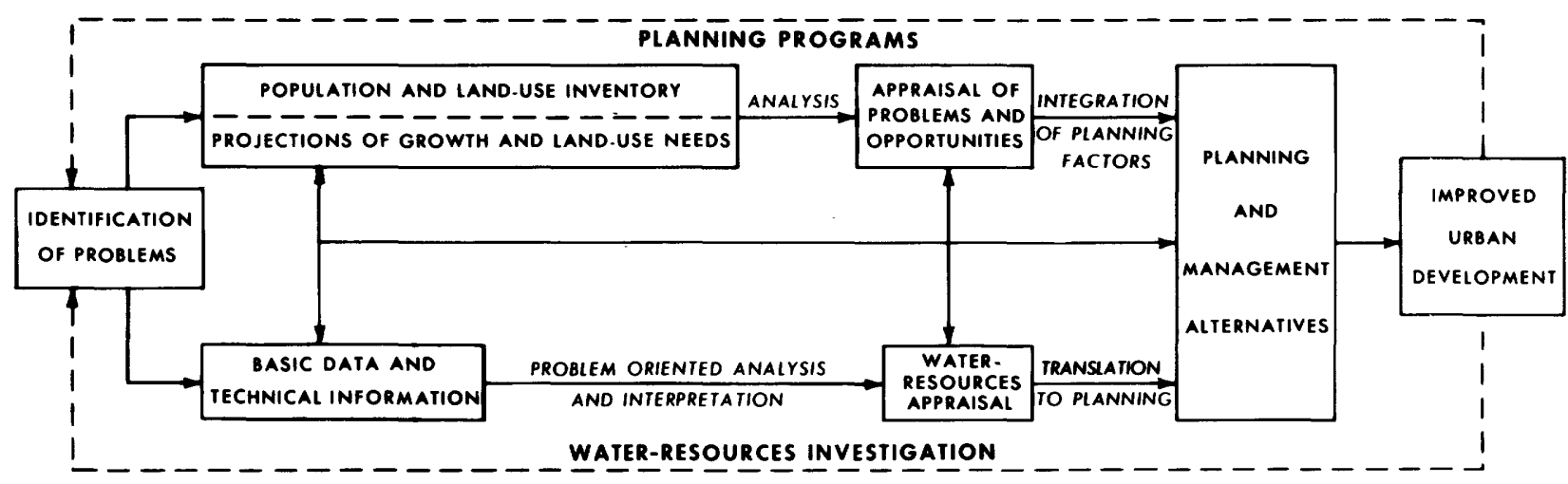

Figure 1.-Simplified flow diagram of the urban planning process showing the interrelation of water-resources investigations and urban planning.

The parallel paths, however, are not mutually exclusive. At any point in the water-resources investigation, available information can be introduced into the planning process. Some basic data and technical information, for example, can be used at all stages of planning. Similarly, each step in the formulation of a plan for urban development can feed back to the waterresources program to enable a continuing reappraisal of the program to insure that this component of the planning program remains relevant.

As the planning efforts progress, the analyses of the basic hydrologic data must of necessity become more complex. Table 1 shows the sequence of hydrologic analysis applied to land use and planning functions. Although only hydrologic factors are listed, geologic, topographic, and demographic inputs are necessary for each successive step in the develorment of the comprehensive planning maps.

\section{HYDROLOGIC ELEMENTS OF UF BAN WATER APPRAISALS}

Appraisals of urban water problems can be both simple or complex. Often may types of hydrologic data are needed for appraisals of but one urban water problem. For some problems, however, specific types of data are needed. A water-resource appraisal, therefore, must be designed with care, and the data and information available must be evaluated in terms of 
TABLE 1.-Sequence of hydrologic analysis applied to land use and planning functior

[Number of variables required for synthesis increases $\rightarrow$ ]

\begin{tabular}{|c|c|c|c|c|}
\hline Basic data & $\begin{array}{l}\text { Basic maps and } \\
\text { sections }\end{array}$ & $\begin{array}{l}\text { 1st Generation, } \\
\text { interpretive planning }\end{array}$ & $\begin{array}{l}\text { 2d Generation, translation } \\
\text { to planning }\end{array}$ & $\begin{array}{l}\text { 3d Gen ?ration, compre- } \\
\text { hensive planning } \\
\text { maps }\end{array}$ \\
\hline $\begin{array}{l}\text { Aquifier data } \\
\text { Ground-water levels } \\
\text { Streamflow measurements } \\
\text { Water-quality data } \\
\text { Precipitation } \\
\text { Evapotranspiration }\end{array}$ & $\begin{array}{l}\text { Water yield } \\
\text { Water-level maps } \\
\text { Hydrographs } \\
\text { Streamflow maps } \\
\text { Well location maps } \\
\text { Depth of water } \\
\text { Water-quality maps }\end{array}$ & $\begin{array}{l}\text { Recharge maps } \\
\text { Water-availability maps } \\
\text { Permeability maps } \\
\text { Pollution susceptability } \\
\text { Transmissivity } \\
\text { Drainage maps } \\
\text { Analog-digital models }\end{array}$ & $\begin{array}{l}\text { Allowable septic tank density } \\
\text { Water-use density } \\
\text { Landfill sites } \\
\text { Foundation suitability }\end{array}$ & $\begin{array}{l}\text { Ultimate design } \\
\text { Land-use compatibility } \\
\text { Alternate choice }\end{array}$ \\
\hline
\end{tabular}

specific objectives. A unifunctional approach that will provide answers to a single problem may be a useless input to other urban water problems.

\section{RELATIONSHIP OF HYDROLOGIC DATA TO URBAN PROBLEMS}

Urban water problems can be broadly classified into nine general categories, which are adequate for broad-scale planning. These urban water problems, in turn, relate to other urban problems, and appraisals from a water-oriented viewpoint must also consider the relation to the general problems.

For example, disposal of solid wastes is a major problem of urban areas, because, in addition to health and logistic problems, pollution is a serious consideration. Water entering the waste material from rainfall or other sources leaches organic and inorganic materials from the waste. This contaminated water tends to move toward the ground-water reservoirs and then to streams. Aquifers and streams can be readily polluted by this process.

The hydrologic aspects of the sanitary landfill problem, while only a small part of the overall problem, are nonetheless complex. If landfill sites are to be selected to minimize ground-water pollution, detailed hydrologic information is needed on the ground-water system. Similarly, information on floods is required if the wastes are to be kept from direct contact with water bodies. Land characteristics such as types of soils and slopes are also required, as are data on climate and existing cultural features. The problem can only be assessed properly by considering pertinent hydrologic information in conjunction with climatic, land, and cultural resources information in terms of the total impact on the entire resource system.

\section{AN EVALUATION MATRIX}

Although a critical need for ws.ter-resource information for urban planning has developed, urban planners are not generally able to identify the hydrologic parameters that are needed for specific water problems. To help bridge this gap, a water-resources evaluation matrix has been developed. The matrix provides a means for determining the relative importance of water-related problems and for identifying the data needed to evaluate these problems for the purpose of urban planning.

The matrix (pl. 1) lists nine subject categories in which water-related urb $n$ problems may occur. Although all categories are not applicable to every urban area, in ag rregate they represent those urban problems that are either water oriented or water dependent. In some areas it is possible that a peculiar wateroriented problem may exist. This problem can easily be accommodated in the matrix by the addition of another column.

The matrix also lists 51 possible data inputs for evaluation of the problem areas. The inputs include the standard types of basic hydrologic data as well as information based on interpretation and analysis of these data. In addition to water-resource items, the list includes the interfacing factors of climate, land, and culture. These factors, especially the cultural, are essential to any appraisal of urban influences on water resources.

The matrix aids in the development of resource evaluation in two ways. First, by promoting interdisciplinary discussior, it leads to a mutual understanding of the water-related problems. Second, it serves as a checklist for determining the data needs for evaluation of each problem. 
In the development of a comprehensive program of water-resource evaluation, ranking of the relative importance of information needs is necessary in order to establish overall program objectives. The matrix lends itself readily to such ranking while simultaneously providing the means for relative ranking of importance of data inputs for each problem area. The ranking of the importance of the information needs of the planners is the first step and requires both dialogue and consensus between the planners and the hydrologists. A suggested format -one developed for the example presented in this circular and used in subsequent appraisals -is a relative ranking on levels: a rank 3 is most important, a rank 2 is moderately important, and a rank 1 is least important. Those having no relevance are excluded and may be considered as having a value of zero.

When the information needs have been ranked, the matrix can be used to determine the relative importance of each data input to that particular urban problem. This is accomplished by ranking each data input as it relates on the same scale ( 3 to 1 ) as the information need. Again, a value of zero applies to input data that are not relevant. The rank assigned is recorded in the lower left section of each box, as indicated on plate 1 . A comparative value can then be assigned to each data component by multiplying the indicated rank of the urban problem and the assigned rank of the data requirement. This value is recorded in the upper right section of each box. The sum of the values in the upper right section of a row of boxes is an index of the relative needs of hydrologic data for a total water-resource evaluation.

Upon completion of the matrix, the hydrologist can determine the availability of data to meet the requirements as identified by the matrix. The need for data-collection programs can then be determined, and the relative ease of such data collection can be assessed. Priorities on work elements can be assigned to provide the planner with maximum information in minimum time.

Thus, the matrix provides both the hydrologist and planner with an appraisal of problems related to water in the urban environment. First, it provides an appraisal of the water- related problems that the planner faces. Second, it provides the hydrologist with a similar appraisal of the problems involved in evaluating the impact of the water resources on the urban problems. Third, it provides for a realistic consideration of water resources as an integral part of urban planning and management. Most significantly, it provides a means of communication between the hydrologist and the planner.

The obvious development from the natrix is a work program that encompasses the full scope of water problems in a set of related work elements. In any metropolitan area, it is not likely that the entire program could be undertaken in a single effort because of the magnitude of the program. However, high-priority work items can be readily identified from the matrix and undertaken in order of priority. The matrix also identifies the overall data requirements for each data element and thus insures that the total need for data is not overlookec in the consideration of one element of the work program.

\section{WASHINGTON-BALTIMORE STUDY CASE}

Plate 1 shows the application of the evaluation matrix to the Washington-Baltimoro urban area. Because of its growth rate and veriety of water problems, this area makes an excellent case study. The area, shown in figure 2, centers around the standard metropolitan statistical areas (SMSA's) of Washington and Baltimore. In addition to this core area, three rapidly growing Maryland counties are included. Together they form an area of 4,530 square miles stretching eastward from the Blue Ridge Mountains to the Chesapeake Bay and southward from the Pennsylvania State lin? to the big bend in the Potomac River.

Although the central cities had a slight decrease in population during 1960-70, rapid growth has occurred in the peripher $>1$ areas within a 25-mile radius of the city centers. Development patterns in the subur's have tended to be erratic, resulting in srrawling growth during which large areas have quickly developed without regard to urban suitability.

The Washington-Baltimore area is a representative slice of the physical environment of the Atlantic seaboard. The geology is complex 


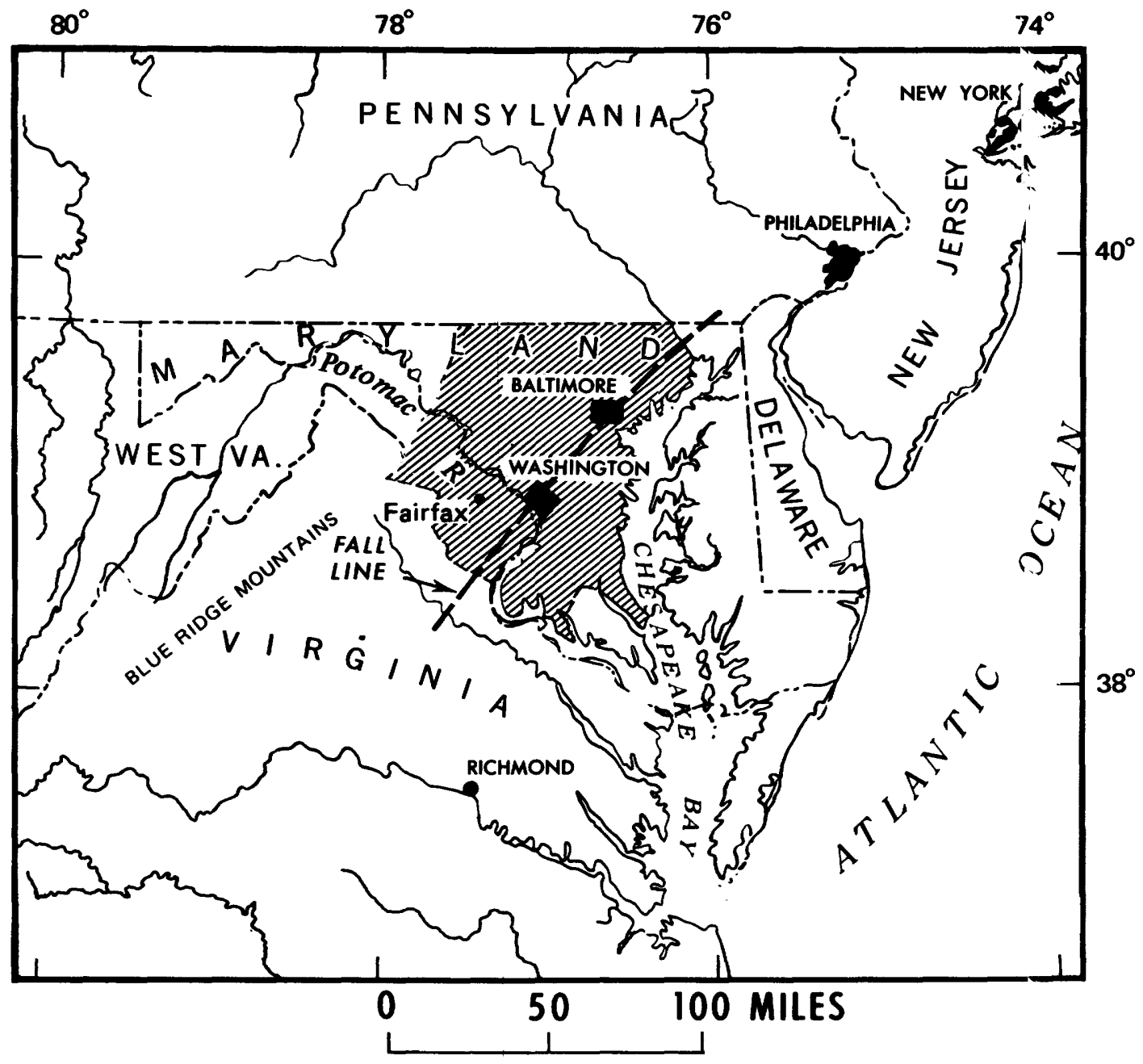

FigURE 2.-Map showing the Washington-Baltimore urban area.

and has strongly influenced the land-use patterns, as well as the availability and development of natural resources. The outstanding natural feature is the Fall Line, which separates the hard rocks of the Piedmont from the unconsolidated or semiconsolidated sediments of the Coastal Plain. The Fall Line follows a low rise of the land trending northeast through Washington and Baltimore. Since colonial times, the Fall Line has divided the region into two different economic areas. For many years the flatter lands of the Coastal Plain were largely planted in tobacco. The rolling hills of the Piedmont, on the other hand, were dairy and stock-raising country. Agricultural uses still occupy the largest areas, but the pattern is rapidly changing with urbanization and industrial growth.
Natural resources are also profoundly different on opposite sides of the Fall Line. For example, the Coastal Plain has abundant ground water both for domestic and industrial use. In the Piedmont, however, ground-water supplies are barely sufficient for domestic use and large developments must depend on surface-water sources.

The hydrology of the Washingtcn-Baltimore region is dominated by the Potome? River and the Chesapeake Bay. Urban planning for the region must provide for continued development of these water bodies while simultaneously protecting them from further degredation.

Consultation with the staff of the Regional Councils of Governments and other planning agencies in the area resulted in rapid identification of water supply, pollution Joading, and 
the estuaries as the critical water-related urban problems. Erosion and sedimentation, existing water quality, and urban drainage were further identified as serious urban water problems. Of lesser importance, but of some concern, were the water-related aspects of solid-waste disposal and esthetics. Land deformation was not deemed to be a problem.

Each ranking (pl. 1) was derived by integrating resource knowledge with knowledge of the present urban conditions and future plans for urban growth. The type of considerations that went into the ranking process can best be illustrated by a few examples.

In,the Washington-Baltimore area, municipal water supply is a critical problem for the entire Washington sector. The municipal supply is taken from the Potomac River, and in recent years at times the demand has almost equaled the flow in the river. Although consideration is being given to use of the upper estuary as an auxiliary supply, upstream reservoirs will probably have to be developed in the Potomac basin. Several plans have been proposed, but all are controversial; as yet no single plan is generally acceptable. The major scope and the critical and unresolved nature of the problem was the basis for giving regional water supply a value of 3 .

The problem of pollution loadings was identified as critical (3), while existing water quality was deemed serious (2). Although knowledge of existing quality is necessary to planning, it is the pollution loadings that primarily controls not only the present but future water quality. The pollution loadings category was thus ranked as a more critical problem. Existing water quality is, nevertheless, a very important problem in the area, so it was given a rank of 2 .

The matrix analysis of data needs indicates that the most important inputs are the cultural factors of population and land use. Although this might appear startling to the hydrologist, one must recognize that water is only one of many resources that an urban planner must consider. The individual resource evaluations must be integrated, and to achieve this, each evaluation must be made in relation to the pivotal factors of population and land use. Hence, these factors serve as the essential basis for any urban water-resource evaluation.
The great need for data on water quality and sources of pollution is consistent with recent trends in urban water problems. Seware and waste disposal works historically have been designed to remove wastes rather than to protect water quality. A burgeoning population and an affluent society have produced more wastes than streams can assimilate, and the public is now demanding changes in the approach to waste disposal. Water pollution is now the most apparent and the most important aspect of urban water-resource management.

\section{SUMMARY AND DISCUSSION}

In the past, land was plentiful and res?urces were abundant. Both were taken for granted, and their uncontrolled development wis for many decades the accepted way of urban growth. Urban growth sprawled acro $₫$ s the landscape without much regard for the ratural resources. Growth for the sake of growth became the goal, and cities competed openl-r with each other for industry and people. Indeed, if resources were considered, it was in terms of exploitation rather than environmental considerations.

The large population shifts following World War II brought about unprecedented urban growth. Gradually, through the 1950's and into the 1960 's, the price of neglect of our resources became apparent. The environment was rapidly becoming despoiled. Untreated sewage from entire cities was discharged to streams, which became open sewers. Floods became more frequent and more intense as urban runoff was accelerated from paved and roofed ares. Today, water problems-especially those of pollution-besiege every urban area. In soms areas they rank along with social and economic issues as a major urban problem.

Indeed, the abuse of our natural resources, especially in urban areas, has brought about a peaceful revolution over protection of cur environment. This attitude, in turn, has brought about a new approach to urban planning - an approach in which consideration of the natural resources, especially water, is a significant factor. To be effective, the new approach requires an input of new types of data to urban planning and ultimately to the decision-making process. Traditionally water-resources data have not 
been interpreted or presented by the hydrologist in a manner whereby it can be readily used by the urban planner. And traditionally, the urban planner has utilized hydrologic data only in terms of water supply and waste disposal.

The new environmental approach to urban planning, however, requires a meaningful input of water-resources information. Developing this input requires continuing communication and contact between the urban planner and the hydrologist in order to insure the relevance of the data. For example, the hydrologist generally has at his disposal information on river stages, but until recently he has not translated these data into flood-inundation maps that planners can use to prevent excessive urbanization of flood-prone areas. On the other hand, planners frequently are unaware that such basic data as river stages can provide them with an effective planning tool to limit encroachment upon flood plains. Recognition of the need for floodinundation information or for means of converting flood-stage data into flood-inundation information has resulted from meaningful dialogues between planners and hydrologists.

The proper interpretation of water-resources data is not only a valuable adjunct to long-range planning, it is also useful to the urban planner in making day-to-day decisions. Such day-today decisions as the design of urban storm drainage, location of sanitary landfills, and permits for septic field drainage all require adequate information on regional water resources that can be obtained from basic hydrologic data. Today, a wealth of water-resources data is available to assist the urban planner in both day-to-day and long-range decisions. These data, however, must be interpreted and supplemented where necessary to provide an adequate basis for decision making. If the environment is to be considered in urban planning, the hydrologist has the responsibility to see that water-resources data are available to the urban planner in usable form, and the urban planner has the responsibility to consider such data in making decisions.

This circular has attempted to develop a rational approach to consideration of water resources in the planning and management of our urban environment. The utility of the approach, however, is dependent upon the relevance of the studies and the approapriateness of the presentation of results. Hydrologic data may be analyzed in many ways. Yet to be relevant, the data must be analyzed in a way that takes into consideration the multifaceted aspects of the entire planning process as well as the restrictions imposed by the management aspects of governmental jurisdictions. The analysis must consider alternatives, and the alternatives must be viable.

The hydrologist has the resporsibility to present a strong documentation of the water resources of the area. He must present both the advantages and disadvantages, from a hydrologic standpoint, of viable alternatives. $\mathrm{He}$ must present the current assessment of the water resource in a clear and firm manner. $\mathrm{He}$ must clearly document the consequences of alternative actions. In doing this, he must work closely with and-perhaps even more-understand urban planning procedures. This is not an easy process; experience has shown that, except in a few cases, communication between the hydrologist and the planner has been one of parallel monologues rather than a meaningful dialogue. The new awareness of our environment, however, has provided botl the need and the motivation for better communication between the hydrologist and the planner.

The final decision on the management of the water resource rests, of course, with the planner. He has the responsibility to vreigh the facts presented by the hydrologist. In the total planning process, water resources must be considered along with all other resources-social, economic, cultural, and physical. If the planner is aware of the hydrologic consequences of his decision, the hydrologist has fulilled his role. 